\title{
Hemorragia espontánea e hipertensión arterial como complicaciones de un pseudoquiste suprarrenal. Presentación de un caso
}

\author{
C.A. Müller Arteaga, S. Martín Blanco, J. Calleja Escudero, J.R. Torrecilla Garcia-Ripoll, \\ D. Rivero Martínez, E. Fernández del Busto
}

Servicio de Urología. Hospital Clínico Universitario de Valladolid. Valladolid.

Actas Urol Esp 2005; 29 (6): 599-602

\section{RESUMEN}

HEMORRAGIA ESPONTÁNEA E HIPERTENSIÓN ARTERIAL COMO COMPLICACIONES DE UN PSEUDOQUISTE SUPRARRENAL. PRESENTACIÓN DE UN CASO

Los pseudoquistes suprarrenales son lesiones muy poco frecuentes y asintomáticas. Se describe un caso de presentación inusual caracterizado por hipertensión arterial previa y sangrado agudo espontáneo manifestado por dolor abdominal y shock. El diagnóstico se realizó por medio de Ecografía y Tomografía computarizada, las cuales demostraron la presencia de un hematoma retroperitoneal importante alrededor de una lesión situada en el polo superior del riñón izquierdo. Se realizó intervención quirúrgica de urgencia con resección completa de la lesión de aproximadamente $10 \mathrm{~cm}$. de diámetro preservando parte del tejido suprarrenal y el riñón izquierdo. El diagnóstico anatomopatológico fue: pseudoquiste suprarrenal. Las cifras tensionales se normalizaron después de la cirugía.

Palabras clave: Glándula suprarrenal. Pseudoquiste suprarrenal. Hemorragia suprarrenal. Shock.

\section{ABSTRACT}

SPONTANEOUS HEMORRHAGE AND ARTERIAL HYPERTENSION AS COMPLICATION OF ADRENAL PSEUDOCYST. REPORT OF A CASE

Adrenal Pseudocyst are uncommon and asymptomatic tumors. We report an unusual case who had previous high blood pressure and acute hemorrhage presented with abdominal pain and shock. Diagnosis was made with ultrasonography and computed tomography revealed the presence of large retroperitoneal hematoma around the superior pole of the left kidney. Urgent surgery was made with a complete excision of a $10 \mathrm{~cm}$. tumor with preservation of adrenal tissue and the left kidney. Hystopathological diagnosis was: Adrenal Pseudocyst. Blood pressure normalized after surgery.

Keywords: Adrenal gland. Adrenal pseudocyst. Adrenal hemorrhage. Shock.

Los quistes suprarrenales son lesiones muy poco frecuentes y generalmente diagnosticadas en autopsias debido a la poca sintomatología que producen. Los avances en los métodos de imagen han aumentado el diagnóstico de estas lesiones como "incidentalomas"; sin embargo, no existen criterios realmente claros de diferenciación en cuanto a su etiología maligna o benigna lo que provoca discusión en el momento de decidir la terapia más adecuada. El propósito del presente articulo es aportar un nuevo caso a la literatura con especial interés en la forma de presentación clínica raramente observada, así como revisar y valorar las posibilidades diagnósticas y terapéuticas.

\section{CASO CLINICO}

Mujer de 68 años con antecedentes de hipertensión arterial e hipotiroidismo, que acude a Urgencias por presentar dolor en hipocondrio izquierdo de presentación aguda, sin antecedentes traumáticos, de carácter constante, irradiado a epigastrio con aproximadamente 3 horas de evolución, acompañado de mareo y debilidad. En 
la exploración física se evidencia hipotensión y taquicardia que se mantiene a pesar de la administración de fluidos intravenosos; el abdomen es doloroso con predominio en hipocondrio y fosa lumbar izquierda sin signos de irritación peritoneal. Se realiza Ecografía y Tomografía computarizada (TC) demostrando la presencia de una tumoración retroperitoneal redondeada de aproximadamente $10 \times 12 \mathrm{~cm}$ por delante del polo superior del riñón izquierdo, vascularizada, con captación del contraste de forma irregular y con pequeñas calcificaciones en su interior; además, se observa un aumento de la densidad del espacio retroperitoneal compatible con sangrado (Figs. 1 y 2). Con los hallazgos antes mencionados se decide intervenir quirúrgicamente evidenciándose un gran hematoma retroperitoneal iz-

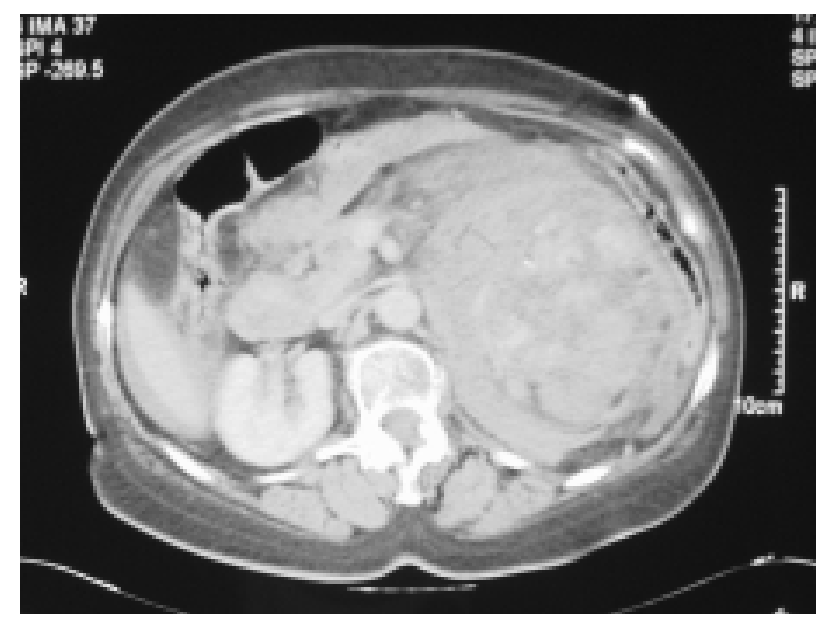

FIGURA 1: Imagen de TAC con aumento de la densidad de espacio perrirenal compatible con sangrado y desplazamiento de estructuras retroperitoneales $e$ intraabdominales, calcificaciones intralesionales.

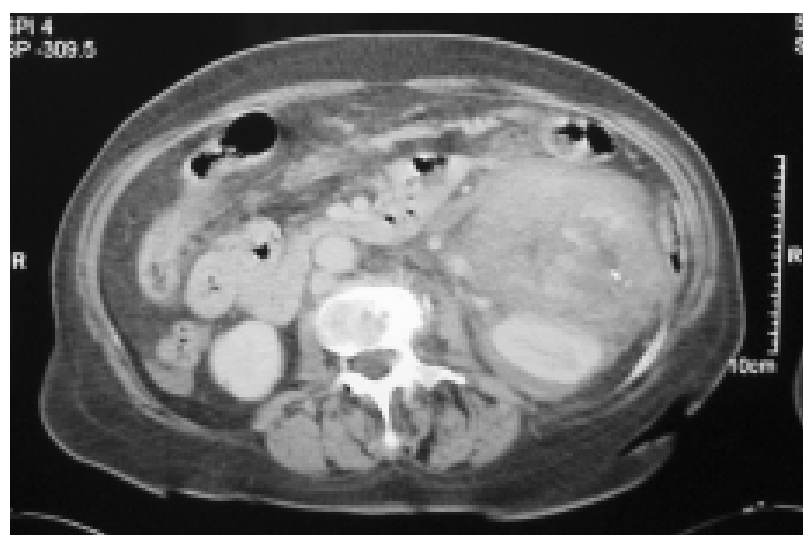

FIGURA 2: Imagen de TAC observando relación del sangrado respecto al riñón. Calcificaciones intralesionales. quierdo que se extiende hasta la línea media y la fosa iliaca izquierda y una tumoración de aproximadamente $12 \mathrm{~cm}$ de diámetro por encima del polo superior del riñón izquierdo, encapsulada, con sangrado activo por fisura en la misma, la cual se extrae preservando parte de la glándula suprarrenal y el riñón izquierdo. La evolución es satisfactoria. La evaluación realizada posteriormente revela la ausencia de hipertensión arterial y en la ecografía abdominal no se observan hallazgos patológicos. La biopsia describe una tumoración nodular de $10 \mathrm{~cm}$ de diámetro y 457 gr. de peso de coloración rojiza con margen periférico de coloración amarillenta, diagnosticándose en el estudio microscópico: Pseudoquiste endotelial suprarrenal.

\section{DISCUSIÓN}

Los quistes de la glándula suprarrenal son lesiones muy poco frecuentes con una incidencia del $0,06 \%$ en autopsias ${ }^{1}$; la primera descripción fue publicada por Greiseleus en $1670^{2}$. De los casos descritos en la literatura, sólo alrededor de 50 corresponden a pseudoquistes suprarrenales y de estos, muy pocos han tenido como forma de presentación la hemorragia espontánea ${ }^{3}$, siendo la mayoría asintomáticos y no funcionantes ${ }^{4}$. La mayor serie publicada en España corresponde a Sanz Mayayo et al. que presentan $6 \operatorname{casos}^{5}$.

Los quistes y tumores suprarrenales representan la cuarta causa de sangrado retroperitoneal espontáneo después del hipernefroma, el angiomiolipoma y los aneurismas de la arteria renal; dentro de la patología suprarrenal, el feocromocitoma es la principal causa ${ }^{6}$.

Para la clasificación de los quistes suprarrenales se usa la propuesta por Abeshouse en 1959, el cual los dividió en los siguientes tipos: quistes parasitarios, quistes congénitos glandulares (de retención), adenomas quísticos, quistes endoteliales y pseudoquistes ${ }^{2}$. La etiología más frecuente de los quistes parasitarios es el Equinoccocus granulosus, este sólo afecta a la suprarrenal en menos del 0,5\% de los casos y representa sólo el $7 \%$ del total de quistes ${ }^{2,5,7,8}$. Los quistes congénitos glandulares y los adenomas quísticos se han unido posteriormente en un solo grupo formando los llamados quistes epiteliales y representan el 9\% de los quistes suprarrenales, son lesiones 
extremadamente raras y deben ser cuidadosamente distinguidos de los pseudoquistes ${ }^{2,3,5,8}$. Los quistes endoteliales pueden ser linfangiomas (los más frecuentes) o hemangiomas ${ }^{2,8}$. Para algunos autores, la variedad más común de lesiones quísticas de la adrenal la representan los pseudoquistes con porcentajes que varian entre el 39 y 56\% según las series, seguidos por los quistes endoteliales ${ }^{2,4}$; sin embargo, en otras publicaciones clasifican a estos últimos como los más frecuentes con un $45 \%^{8}$.

Los quistes suprarrenales pueden ser uniloculares o multiloculares, generalmente únicos, siendo bilaterales sólo en el 10\% de los casos. Su tamaño es muy variable, pudiendo incluso llegar a medir hasta más de $20 \mathrm{~cm}$ de diámetro ${ }^{3,4,5,9}$. Son más frecuentes en las mujeres con una proporción de 2-3:1 con respecto a los varones, entre la cuarta y sexta década (alrededor de los 45 años) y afectan con una discreta mayor frecuencia (52\%) al lado izquierdo ${ }^{1-3,5}$.

Los pseudoquistes carecen de capa endotelial de revestimiento, por lo que no son quistes verdaderos, su cápsula esta compuesta por una pared fibrosa que los reviste y habitualmente presenta calcificaciones. El origen más probable de estos es el sangrado suprarrenal espontáneo con posterior organización (extravasación, necrosis, licuefacción y encapsulación) ${ }^{2,8,9}$; de esta forma se han postulado como probable etiología los traumatismos, la sepsis, el shock, el sangrado por diátesis hemorrágica o el tratamiento anticoagulante y la degeneración de tumores, entre otros $^{2,3,5,6,8-10}$. Estudios recientes han demostrado el origen vascular de los mismos a través de la expresión del antígeno relacionado con el factor VII, laminina y CD34, en ausencia de antígenos de membrana o queratina ${ }^{4}$.

En cuanto a sus manifestaciones clínicas, son asintomáticos en la mayoría de los casos, descubriéndose generalmente como incidentalomas en exploraciones realizadas por otras causas; cuando presentan manifestaciones clínicas, estas generalmente son debidas a la compresión de órganos vecinos por el crecimiento del quiste y, de manera excepcional se presentan con la sintomatología derivada del sangrado del mismo, como en el caso presentado. Otras manifestaciones incluyen: dolor lumbar o abdominal, masa palpable, o síntomas derivados de la infección del quiste $^{1-3,6}$. También se han descrito alteraciones gastrointestinales (obstrucción del tracto de salida gástrico) e hipertensión arterial sin estar totalmente definido el mecanismo por el cual se produce $^{4,5}$, como ocurrió en el caso que describimos con mejoría posterior de las cifras tensionales al ser extirpada la lesión.

Los métodos más utilizados para el diagnóstico son la Ecografía y TC, que revelan lesiones de naturaleza quística o mixta, generalmente con calcificaciones producto del sangrado previo ${ }^{1,3,9}$. Se ha descrito que el $56 \%$ de los pseudoquistes presentan calcificaciones en su pared, las cuales se encuentran relacionadas con sangrado en el mismo aproximadamente 1 año antes ${ }^{6}$. Las características ecográficas varían de acuerdo al tiempo de sangrado, siendo generalmente de ecogenicidad mixta con área central hipoecoica que posteriormente puede llegar a ser anecoica con refuerzo posterior; las calcificaciones se pueden comenzar a observar en la periferia hasta 2 semanas después del sangrado ${ }^{5,6}$. En la TC se observa un quiste bien definido que contiene áreas de alta atenuación, presentando con el sangrado un área central de baja atenuación ${ }^{6,9}$. De acuerdo a los hallazgos tomográficos pueden clasificarse en quistes no complicados (menores de 5 a $6 \mathrm{~cm}$, pared menor de $3 \mathrm{~mm}$ ), quistes complicados (pared mayor de $5 \mathrm{~mm}$, textura no heterogénea, calcificación periférica gruesa o central) y, un grupo indeterminado (con características intermedias entre los anteriores) ${ }^{5}$. Los quistes endoteliales generalmente son multiloculares y con calcificaciones $^{3}$.

También pueden ser útiles la Resonancia Magnética (RMN) y la arteriografía para valorar la hemorragia $^{1,9}$. La RMN hace evidentes las multiloculaciones, sin embargo, es de poca ayuda para observar calcificaciones ${ }^{6}$. La arteriografía es poco usada y los hallazgos que revela no son diagnósticos, sin embargo, sirve para evaluar el aporte sanguíneo suprarrenal y el contorno de la lesión o hematoma La radiografía simple y la urografía intravenosa son útiles cuando existen dudas acerca del origen del sangrado: suprarrenal o de órganos vecinos ${ }^{6}$. La punción-aspiración con aguja fina (PAAF) del quiste con estudio citológico y bioquímico puede ser útil para descartar la 
malignidad del mismo, así como para diferenciar su origen cuando se presenten dudas $3,5,6$. Los estudios con radioisótopos $\left(\mathrm{Tc}^{99}\right)$ no son usados de rutina, aun cuando permiten la valoración de quistes suprarrenales a través de la escasa captación del material ${ }^{6}$. También se ha planteado como estudio diagnóstico la quistografia, siendo criterios de benignidad la presencia de pared lisa ${ }^{5}$.

Debido al aumento del diagnóstico de los quistes y pseudoquistes adrenales como incidentalomas, cada vez se plantean mayores discusiones en cuanto a la mejor opción terapéutica cuando se sospecha su naturaleza benigna ${ }^{3}$. Sólo el $7 \%$ son malignos o potencialmente malignos ${ }^{5}$, sin embargo, esta sospecha se establece en un gran porcentaje de casos por la tendencia de estas lesiones a formar adherencias con las estructuras vecinas mimetizando a los tumores malignos $^{8}$; así, las características que hacen sospechar malignidad son: la heterogeneidad en los estudios de imágenes, el tamaño superior a los $7 \mathrm{~cm}$, las calcificaciones en el interior de la lesión y la presencia de pared gruesa (mayor de $0,5 \mathrm{~cm}$ ) ${ }^{3,6}$. El tamaño inferior a los $2 \mathrm{~cm}$ y la presencia comprobada de sangre en los quistes sugiere su naturaleza benigna (este es uno de los principales motivos del uso de la RMN en el estudio y seguimiento de esta lesión) ${ }^{6,7}$.

En el diagnóstico diferencial se deben incluir patologías como el adenocarcinoma quístico suprarrenal, los feocromocitomas con componente quístico y los tumores renales: hipernefromas quísticos del polo superior del riñón, metástasis, así como lesiones quísticas de órganos vecinos ${ }^{2,3,5,6}$; por esto se recomienda, en la medida de lo posible, la realización de biopsias de la pared del quiste o PAAF del contenido, así como estudios hormonales ante la presencia de esta patologia ${ }^{3,5,7}$.

Las opciones de tratamiento incluyen la observación periódica mediante controles tomográficos o de RMN, el drenaje del quiste (por punción o a cielo abierto) y la resección quirúrgica ${ }^{1,5}$. La decisión terapéutica estará basada en las características del mismo, la sospecha de enfermedad maligna, la sintomatología que produzca y las posibilidades de sangrado por ruptura del mismo en los que presenten gran tamaño. Generalmente todas las lesiones terminan en cirugía, bien por las características del quiste, la sintomatología o las dudas diagnósticas ${ }^{5}$.

Entre los planteamientos de cirugía abierta se describen la enucleación del pseudoquiste, la resección en conjunto con la glándula suprarrenal y/o riñón y la marsupialización del mismo cuando no sea posible la disección de las adherencias a otros órganos ${ }^{1,2}$. Es importante preservar en la medida de lo posible la glándula suprarrenal así como el riñón, lo cual en ocasiones puede estar dificultado por las características del pseudoquiste o las condiciones de la cirugía en caso de hemorragia aguda como ocurrió en el caso que describimos.

\section{REFERENCIAS}

1. Arribas del Amo D, Val-Carreces Guinda A, Escartín Arias A, Elia Guedea M, Aguilella Diago V, Martínez Díez M. Pseudoquiste suprarrenal: dos casos manifestados por dolor abdominal agudo y shock. Arch Esp de Urol 2001;54 (2):173-176.

2. Abeshouse G, Goldstein R, Abeshouse B. Adrenal cyst: Review of the literature and report of three cases. J Urol 1959;81:711-719.

3. Martín Fernández J, Delgado Portela M, Ladrón Gil C, et al. Pseudoquistes suprarrenales. Actitud terapéutica. Arch Esp de Urol 1998;51(8):761-765.

4. Karayiannakis A, Polychronidis, A, Simopoulos, C. Giant adrenal Pseudocyst presenting with gastric outlet obstruction and hypertension. Urology. 2002; 59: 946viii-946ix.

5. Sanz Mayayo E, Maganto Pavón E, Gómez García I, et al. Quistes suprarrenales: Presentación de seis casos. Arch Esp Urol 2003;56(4):345-353.

6. Kawashima A, Sandler C, Ernst R, et al. Imaging of Nontraumatic Hemorrhage of the Adrenal Gland Radiographics 1999;19:949-963.

7. García Ramos JB, Medina López RA, Pereda Salguero T, Campoy Martínez P, Ramírez Mendoza A, Soltero Martínez A. Pseudoquiste suprarrenal. Presentación de un nuevo caso. Actas Urol Esp 1999;23(1):72-75.

8. Ghandur-Mnaymneh L, Slim M, Muakassa K. Adrenal cyst: Pathogenesis and histological identification with a report of 6 cases. J Urol 1979;122:87-91.

9. Sakamoto Y, Nakayahara N, Fukuda T, Nagayoshi K, Matsunaga N, Hayashi K. Appearance of adrenal pseudocyst. J Urol 1994;152:150-152.

10. Juvenois A, Lefebvre P, Ansay J. Observation d'un pseudokyste hemorragique surrenalien. Revue de la littérature. Acta Clin Belg 1993;48(2):119-123.

Dr. C. Müller Arteaga

Servicio de Urología.

Hospital Clínico Universitario de Valladolid

Avda. Ramón y Cajal, 3

47005 Valladolid

(Trabajo recibido el 4 octubre 2004) 